\title{
Mesoporous materials as fining agents in variety Cabernet Sauvignon wines
}

\author{
Georgiana-Diana Dumitriu ${ }^{1}$, Valeriu V. Cotea ${ }^{1}$, Rafael A. Peinado ${ }^{2}$, Nieves Lopez de Lerma ${ }^{2}$, Camelia Elena Luchian ${ }^{1}$, \\ Cintia Lucia Colibaba ${ }^{1}$, Marius Niculaua ${ }^{3}$, Cătălin-Ioan Zamfir ${ }^{3}$, Florin Vararu ${ }^{1}$, and Gheorghe Odăgeriu ${ }^{3}$ \\ ${ }^{1}$ University of Agricultural Sciences and Veterinary Medicine "Ion Ionescu de la Brad" Iaşi, Department of Viticulture and Oenology, \\ 700490, no 3, Mihail Sadoveanu Alley, Iaşi, România \\ ${ }^{2}$ University of Cordoba, Department of Agricultural Chemistry, Building Marie Curie, $3^{\text {th }}$ floor, Campus of Rabanales, 14104 \\ Cordoba, Spain \\ ${ }^{3}$ Oenological Research Center, Romanian Academy Iasi Branch, 700490, no 9, Mihail Sadoveanu Alley, Iaşi, România
}

\begin{abstract}
Innovative oenological products and techniques constantly need to be optimized in order to produce high quality wines that are able to fulfill the demanding consumers, with a pleasant colour, astringency, bitterness and a balanced organoleptic profile. New mesoporous materials with viability and environmental safety characteristics, might be a feasible alternative to the use of bentonite, while nowadays in the winemaking there is a major challenge caused by wastes derivate mainly from wine clarification stages. This study was aimed at investigating the influence of conventional (bentonite and activated coal) and alternative (MCM-41, SBA-15, KIT-6) fining agents on enological parameters, colour, as well as on the antioxidant activity of a Cabernet Sauvignon wines. Our results show that mesoporous materials, KIT-6 and SBA-15 (6g/L) present the highest reduction on antioxidant activity with $23.08 \%$ and $24.41 \%$, while bentonite and activated coal $(1.5 \mathrm{~g} / \mathrm{L})$ reduced with $20.72 \%$, respectively $33.18 \%$. Cluster analysis performed with the values of antioxidant activity differentiated wines treated with activated carbon from other wines.
\end{abstract}

\section{Introduction}

Innovative oenological practices constantly need to be discovered and investigated in order to contribute to the development of high quality wines that have the ability to fulfill even the most demanding consumers.

A comprehensive area of various fining agent have been tested in recent years and hence, fining is yet one of the most conventionally used techniques in winemaking, for promote efficient clarification and stabilization processes $[1,2]$.

Currently fining products might be composed by animal, mineral and vegetable particles [3] or even by mixed formulations that combine a miscellaneous of distinct compounds, trying to simultaneously promote parallel effects on wines. The main effect of bentonite is protein precipitation by adsoption and neutralization charge, potassium caseinate mainly to remove oxidizable and oxidized phenolic compounds by adsoption [4] and poly-vinylpoly-pirrolidone (PVPP) is used to remove phenolic compounds.

Bentonite, montmorillonite clay, is the most commonly used fining agent in the wine industry that can be used to stabilize wine against the precipitation of soluble grape proteins, which can occur in wine when it passes through temperature increase. The essential important factor of bentonite is its ability to adsorb proteins in grape juice and wine, and it is this especial primary characteristic that makes it so important in winemaking. This adsorption results from either an electrostatic attraction between positively charged proteins or the negatively charged bentonite (at wine $\mathrm{pH}$ ). Bentonite is not a selective absorber and may reduce other positive compounds of wine. Therefore the quantity of bentonite to be used should be as low as possible [5]. Three major mechanisms of action of fining agents include charge-charge (electrical) interaction, bond formation, or absorption/adsorption. Bentonite and activated coal adsorption have an effect on aroma and flavor factors inducing in some situations aroma loss or colorless wines. Also, causes substantial volume losses (between 3\% and 10\%) and the disposal of spent bentonites constitute a non-negligible source of waste. Finally, bentonite handling is also of concern on account of occupational health and safety issues [6].

New mesoporous materials with viability and environmental safety characteristics might be a feasible alternative to the use of bentonite, while nowadays in the winemaking there is a major challenge caused by wastes derivate mainly from wine clarification stages.

Ordered mesoporous materials are an important class of molecular sieve that are composed of extensively ordered arrays with pore size of $2-50 \mathrm{~nm}$ and surface areas up to $1000 \mathrm{~m}^{2} / \mathrm{g}$. Mesoporous materials have been widely used in chemical sensing, adsoption, molecular separation, photonics, drug delivery, catalysis, etc., because of their high surface area, tunable pore sizes and shapes, a multitude of compositions, high hydrothermal and mechanical stability [7]. 
Table 1. Types and characteristics of nanomaterials. SSA: specific surface area, PD: pore diameter, PS: particle size.

\begin{tabular}{|l|c|c|c|}
\hline Nanomaterial & KIT-6 & MCM-41 & SBA-15 \\
\hline SSA $\left(\mathbf{m}^{2} / \mathbf{g}\right)$ & $600-800$ & $850-850$ & 600 \\
\hline PD $(\mathbf{n m})$ & $8-10$ & $3.4-5.0$ & $7-10$ \\
\hline PS $(\boldsymbol{\mu m})$ & $10-100$ & $100-1000$ & $1-2$ \\
\hline
\end{tabular}
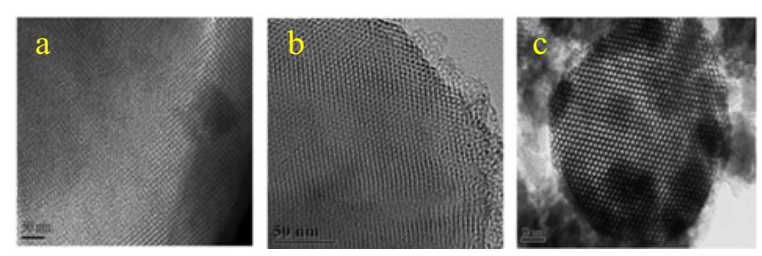

Figure 1. Transmission electron microscopy images of nanomaterials: KIT-6 (a), MCM-41 (b) and SBA-15 (c).

Mesoporous silica, as novel fining treatments, are able on their own to react with and precipitate beverage protein colloids, thus increasing the protein stability, the deposit is more dense and settles more quickly. Mesoporous materials are suitability for immobilization or inhibition different enzyme [8] also as adsorption and separation of amino acids [9] and trace metals from aqueous solution showed very high affinities to the mesoporous adsorbent.

This study was aimed at investigating the influence of conventional (bentonite and activated coal) and alternative (MCM-41, SBA-15, KIT-6) fining agents on enological parameters, colour, as well as on the antioxidant activity of a Cabernet Sauvignon wines.

\section{Material and methods}

\subsection{Winemaking process}

Cabernet Sauvignon grape variety ( $V$. vinifera) harvested in 2014 in the Ia? $\mathrm{i}$ vineyard. The marc obtained was subjected to a maceration-fermentation process at temperature of $10-12^{\circ} \mathrm{C}$, for 14 days and was inoculated with selected yeast. Then, the must was pressed and the wines obtained were transferred in tanks for the completing of alcoholic and malolactic fermentation. After the completion of the alcoholic fermentation, wines were removed from the yeast deposit and subjected to a spontaneous fining process using various materials.

$2 \mathrm{~g} / \mathrm{L}$ and $6 \mathrm{~g} / \mathrm{L}$ of three types of nanomaterials (Table 1, Figure 1) were added at three samples of wine. Also we realized two other variants using bentonite $(1 \mathrm{~g} / \mathrm{L}$ and $1.5 \mathrm{~g} / \mathrm{L})$ and activated coal $(1 \mathrm{~g} / \mathrm{L}$ and $1.5 \mathrm{~g} / \mathrm{L})$. The control variant was obtained without any addition of materials. All samples were performed in three repetitions for each.

The obtained solutions were stirred half of hour in hermetic glass flask and left 24 hours at $5^{\circ} \mathrm{C}$ temperature. The resulting variants were centrifuged at $5000 \mathrm{rpm}$ and $4^{\circ} \mathrm{C}$ for 10 minutes.

\subsection{Enological parameters}

Wine samples were analyzed for determining the basic physico-chemical parameters: $\mathrm{pH}$ (OIV-MA-AS31315), total acidity (OIV-MA-AS313-01), volatile acidity
(OIV-MA-AS313-02) and alcohol strength (OIV-MAAS312-01A). All analyses were determined according to the with European and O.I.V. standards [10].

\subsection{Absorbance measurements}

Prior to analyses the samples were filtered through a HA$0.45 \mu \mathrm{m}$ paper (Millipore, Milford, MA). The wine colour was assessed by the CIE Lab 76 method (OIV, 2000). The CIE-L*a*b* system is a three-dimensional chromatic colour space, which was established by the International Commission on Illumination, in French 'commission internationale de l'eclairage': CIE. The main CIELAB parameters $\left(\mathrm{L}^{*}, \mathrm{a}^{*}, \mathrm{~b}^{*}\right)$ were calculated. The $\mathrm{L}^{*}$ describes the lightness of the colour $\left(\mathrm{L}^{*}=0\right.$ black and $\mathrm{L}^{*}=100$ colourless), $\mathrm{a}^{*}$ value represents the difference between green $\left(\mathrm{a}^{*}<0\right)$ and red $\left(\mathrm{a}^{*}>0\right), \mathrm{b}^{*}$ indicates the difference between blue $(b *<0)$ and yellow $(b *>0)$.

\subsection{Total antioxidant activity}

Antioxidant activity was measured with the blue/green chromophore $\mathrm{ABTS}^{+}$method described by Re et al. [11]. The ABTS ${ }^{+}$was produced by oxidation of $7 \mathrm{mM}$ ABTS with $2.45 \mathrm{mM}$ potassium persulphate in conditions of darkness for $12-16 \mathrm{~h}$. The resulting $\mathrm{ABTS}^{+}$solution was diluted in $20 \mathrm{mM}$ phosphate buffer at $\mathrm{pH} 7.4$ to obtain an absorbance at $734 \mathrm{~nm}$ of 0.7 . A volume equal to or greater than $900 \mu \mathrm{L}$ of this test mixture was reacted with a volume equal to or less than $100 \mu \mathrm{L}$ of wine samples, previously filtered through HA-0.45 $\mu \mathrm{m}$ papers (Millipore, Milford, MA), for $6 \mathrm{~min}$. After this time, the absorbance at $734 \mathrm{~nm}$ of the reaction mixture was measured. Antioxidant activity was measured in terms of the proportion of $\mathrm{ABTS}^{+}$ inhibited: \% inhibition $=($ A734 blank - A734 sample $) \times$ 100/A734 blank. This percentage of inhibition should fall in the range $20-80 \%$. The samples were previously filtered through HA-0.45 $\mu \mathrm{m}$ paper (Millipore, Milford, MA).

\subsection{Statistical treatment}

All analyses were made for triplicate and a homogeneous group's analysis was made by means of the statistical package Statgraphics Centurion XVI from StatPoint Technologies, Inc. (Warrenton, VI, USA) to study if there were significant differences among the samples in the determined parameters. Cluster analyses using Ward's method were carried out in order to group the wine samples according fining agents using as classifying variables total antioxidant activity of the wines.

Lastly, a scatterplot 3D was performed with $\mathrm{R}$ 3.3.0 language and environment and $\mathrm{R}$ packages scatterplot $3 \mathrm{~d}$ was used.

\section{Results and discussion}

The results of the conventional chemical analysis for variants of red wines with different treatment are illustrated in Table 2. These are similar and within the usual values recorded for red wines from the Romania North-East region. We observed that control sample has a higher value for the total acidity ( $\mathrm{g} / \mathrm{L}$ tartric acid) then all other samples. The ethanol content in all Cabernet Sauvignon variants were $13.16 \pm 0.00$. Enological parameters of treated wines showed slight decreases in respect to control. This may 
Table 2. Enological parameters of Cabernet Sauvignon wines after treatments. TA: titratable acidity (g tartaric acid/L), VA: volatile acidity (g acetic acid/L); Different letters indicate significant differences at 95\% confidence level. Data expressed as mean \pm standard deviation.

\begin{tabular}{|l|c|c|c|c|}
\hline Sample & $\mathrm{pH}$ & TA & VA & Ethanol (\% v/v) \\
\hline CONTROL & $3.23 \pm 0.01^{\mathrm{a}}$ & $5.75 \pm 0.00^{\mathrm{i}}$ & $0.56 \pm 0.02^{\mathrm{e}}$ & $13.16 \pm 0.00^{\mathrm{a}}$ \\
\hline KIT-6 $(2 \mathrm{~g} / \mathrm{L})$ & $3.24 \pm 0.01^{\mathrm{b}}$ & $5.65 \pm 0.04^{\mathrm{j}}$ & $0.55 \pm 0.00^{\mathrm{d}}$ & $13.16 \pm 0.00^{\mathrm{a}}$ \\
\hline KIT-6 $(6 \mathrm{~g} / \mathrm{L})$ & $3.23 \pm 0.01^{\mathrm{a}}$ & $5.63 \pm 0.07^{\mathrm{g}}$ & $0.55 \pm 0.00^{\mathrm{d}}$ & $13.16 \pm 0.00^{\mathrm{a}}$ \\
\hline MCM-41 $(2 \mathrm{~g} / \mathrm{L})$ & $3.24 \pm 0.00^{\mathrm{b}}$ & $5.73 \pm 0.04^{\mathrm{h}}$ & $0.47 \pm 0.00^{\mathrm{a}}$ & $13.16 \pm 0.00^{\mathrm{a}}$ \\
\hline MCM-41 $(6 \mathrm{~g} / \mathrm{L})$ & $3.24 \pm 0.01^{\mathrm{b}}$ & $5.63 \pm 0.09^{\mathrm{f}}$ & $0.47 \pm 0.00^{\mathrm{a}}$ & $13.16 \pm 0.00^{\mathrm{a}}$ \\
\hline SBA-15 $(2 \mathrm{~g} / \mathrm{L})$ & $3.37 \pm 0.01^{\mathrm{d}}$ & $5.55 \pm 0.04^{\mathrm{e}}$ & $0.54 \pm 0.00^{\mathrm{c}}$ & $13.16 \pm 0.00^{\mathrm{a}}$ \\
\hline SBA-15 $(6 \mathrm{~g} / \mathrm{L})$ & $3.37 \pm 0.01^{\mathrm{d}}$ & $5.05 \pm 0.01^{\mathrm{a}}$ & $0.54 \pm 0.00^{\mathrm{c}}$ & $13.16 \pm 0.00^{\mathrm{a}}$ \\
\hline BENTONITE $(1 \mathrm{~g} / \mathrm{L})$ & $3.24 \pm 0.01^{\mathrm{b}}$ & $5.20 \pm 0.02^{\mathrm{b}}$ & $0.53 \pm 0.00^{\mathrm{b}}$ & $13.16 \pm 0.00^{\mathrm{a}}$ \\
\hline BENTONITE $(1.5 \mathrm{~g} / \mathrm{L})$ & $3.25 \pm 0.01^{\mathrm{c}}$ & $5.75 \pm 0.04^{\mathrm{i}}$ & $0.53 \pm 0.00^{\mathrm{b}}$ & $13.16 \pm 0.00^{\mathrm{a}}$ \\
\hline ACTIVATED COAL $(1 \mathrm{~g} / \mathrm{L})$ & $3.38 \pm 0.00^{\mathrm{e}}$ & $5.35 \pm 0.01^{\mathrm{c}}$ & $0.53 \pm 0.00^{\mathrm{b}}$ & $13.16 \pm 0.00^{\mathrm{a}}$ \\
\hline ACTIVATED COAL $(1.5 \mathrm{~g} / \mathrm{L})$ & $3.38 \pm 0.01^{\mathrm{e}}$ & $5.36 \pm 0.01^{\mathrm{d}}$ & $0.53 \pm 0.00^{\mathrm{b}}$ & $13.16 \pm 0.00^{\mathrm{a}}$ \\
\hline
\end{tabular}

be due to the interaction of nanomaterials with the components of wine or to the displacement of the chemical balances by the change of $\mathrm{pH}$. Anyway, nanomaterials contribute to reduce the volatile acidity, parameter which is related to analytical quality of wine.

Wine (particularly the red wine) contains large amounts of phenolic compounds that constitute a good source of antioxidant which have several health benefits [12].

Fining agents are widely used to adjust levels of tannins or polymeric phenols [13,14]. These compounds, particularly oxidative phenols, may inadvertently contribute to haze by reacting with residual protein fractions, eventually precipitating out of solution and causing turbidity [15]. Tannins and phenol compounds are responsible for the astringent mouthfeel perceived when consuming astringent wines and fining agents help to reduce or soften highly astringent wines prior to bottling by reducing the tannin content [16].

Our results show that mesoporous materials, KIT6 and SBA-15 (6g/L) present the highest reduction on antioxidant activity with $23.08 \%$ and $24.41 \%$, while bentonite and activated coal $(1.5 \mathrm{~g} / \mathrm{L})$ reduced with $20.72 \%$, respectively $33.18 \%$. Also, the results shown that the total antioxidant activity decreased proportional with the quantity of fining agents added (Fig. 2).

Nanomaterials present a selective effect on the phenolic compounds due to their structure when compared with bentonite and activated coal. They have the possibility to retain specific chemical compounds in a larger quantity, based on this properties.

The term "cluster analysis" encompasses a large variety of algorithms and methods used to classify samples into groups in such a way that the degree of association between two samples will be maximal if they fall in the same group and minimal otherwise. The smaller the distance between clusters, the greater is their similarity. Cluster analysis is the most popular from the multivariate techniques with many applications in the field of food science and technology [17]. In the cluster analysis the primary purpose is to aggregate individuals based on their characteristics, forming groups with greatest possible

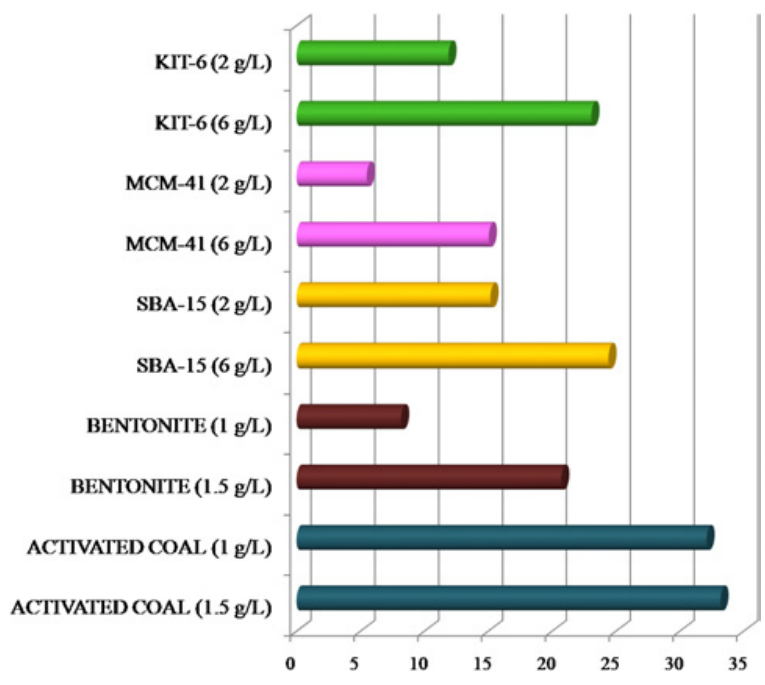

Figure 2. The percentage of reduction of total antioxidant activity (expressed as millimolar of trolox) in wines after the fining treatment.

internal homogeneity (within groups) and greatest possible external heterogeneity (between groups).

As can be seen, two distinct clusters were formed in the Fig. 3. The first one distinguished the wines treated with mesoporous materials (KIT-6, MCM-41 and SBA15), the control and bentonite wines. In the second cluster are distinguished only the wines treated with activated coal.

Colour is one of the principal attributes of a wine and it represents a decisive factor for the choice of consumers. In this regard, colour studies can be a helpful tool in oenological practices in the recognition of the typical characteristics of a wine.

The $a^{*}$ and $b^{*}$ values did not significantly differ between treatments in the Cabernet Sauvignon wines treated with mesoporous materials. The $\mathrm{L}^{*}$ value of SBA15 (10.17) was higher than the other treatments with nanomaterials. The lowest mean $\mathrm{L}^{*}$ value was recorded for MCM-41 (9.15). Concerning parameters $L^{*}, a^{*}$ and $b^{*}$, treatments with bentonite and activated coal increased the 


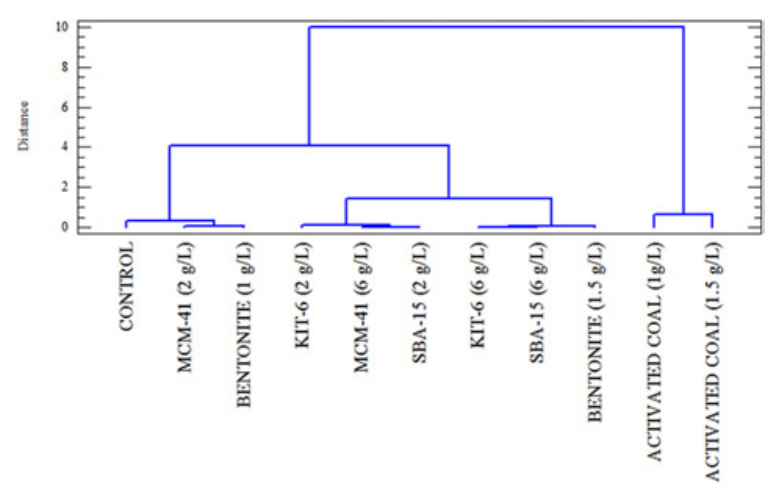

Figure 3. Cluster analyses of Cabernet Sauvignon wines after treatment with fining agents.

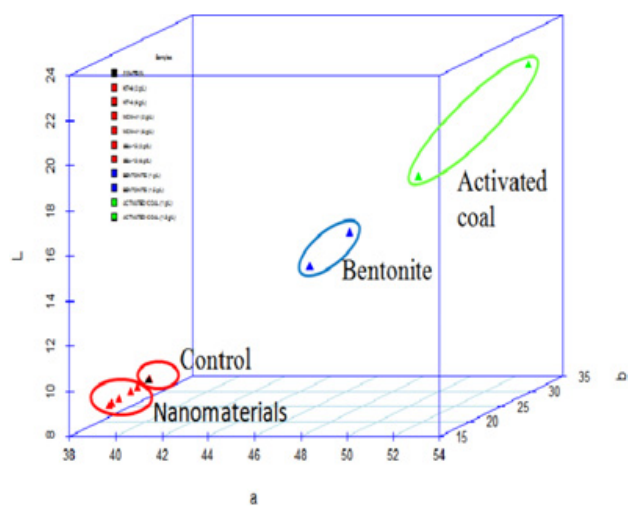

Figure 4. 3D representation of CIELAB chromatic coordinates $(\mathrm{L} *, \mathrm{a} *$ and $\mathrm{b} *$ ) of Cabernet Sauvignon red wines.

values with quantity dependent on the fining agent added. Cabernet Sauvignon fined with activated coal reduced most efficient the color intensity. CIELab chromatic coordinates $\mathrm{a}^{*}, \mathrm{~b}^{*}$ and $\mathrm{L}^{*}$ were represented in a 3D plot (Fig. 4) and show a significantly difference between samples treated with nanomaterials and those treated with traditional fining agents (bentonite and activated coal).

\section{Conclusions}

Nanomaterials present a selective effect on the antioxidant activity due to their structure when compared with bentonite and activated coal. Cluster analysis performed with the values of antioxidant activity differentiated wines treated with activated carbon from other wines.

Concerning the color parameters, a minor loss can be seen in relation with the control.

Use of new mesoporous materials as fining agents could represent a promising alternative for improving the quality of wines, that currently are fined with bentonite and activated coal, while nowadays in the winemaking there is a major challenge caused by wastes derivate mainly from wine clarification stages.

This paper was carried out under the frame of OIV Research Grant. We are also grateful to the Oenological Research CenterRomanian Academy, Iasi Branch.

\section{References}

[1] M. Marangon, M. Lucchetta, D. Duan, V.J. Stockdale, A. Hart, P.J. Rogers. Aust. J. Grape Wine Res 18, 194-202 (2012)

[2] M. Lucchetta, K.F. Pocock, E.J. Waters, M. Marangon. Am. J. Enol. Vitic 64, 400-404 (2013)

[3] R. Marchal, P. Jeandet. Wine chemistry and biochemistry, 127-158 (2009)

[4] M. Manfredini. Vignevini 16(3), 47-50 (1989)

[5] K. Schmitt. Kellerwirtschaftlicher Informations Service (2012)

[6] F.X. Sauvage, B. Bach, M. Moutounet, A. Vernhet. Food Chemistry 118, 26-34 (2010)

[7] W. Li, D.Y. Zhao. Chem. Commun 49, 943-946 (2013)

[8] N. Kupferschmidt, R.I. Csikasz, L. Ballell, T. Bengtsson, A.E. Garcia-Bennett. Nanomedicine 0, 1-9 (2014)

[9] S. Ernst, M. Hartmann, S. Munsch. Stud. Surf. Sci. Catal 135, 308 (2001)

[10] OIV. Paris - Organisation International de la Vigne et du Vin (2015)

[11] R. Re, A. Pellegrini, A. Pannala, M. Yang, C. Rice-Evans. Free Radical Bio. Med 26, 1231-1237 (1999)

[12] D. Dumitriu, R.A. Peinado, J. Peinado, N. López de Lerma. J Funct Foods 17, 380-387 (2015)

[13] E. Gómez-Plaza, R. Gil-Muñoz, J.M. López-Roca, M.L. Hera-Orts, A. Martínez-Cultíllas. J. Wine Res 11(3), 223-231 (2000)

[14] S. Girotti, F. Fini, L. Bolelli, L. Savini, E. Sartini, G. Arfelli. Lumine 21, 233-238 (2006)

[15] L. Armada, E. Falqué. Eur. Food Res. Technol 225, 553-558 (2007)

[16] C. Maury, P. Sarni-Manchado, L. Sandrine, V. Cheynier, M. Moutounet. Am. J. Enol. Vitic 52(2), 140-145 (2001)

[17] H. Muller, U. Hamm. Food Qual. Prefer. 34, 70-78 (2014) 